\title{
Legislação trabalhista nas relações de trabalho do cirurgião-dentista
}

\author{
Labor legislation in work relationships of dentists
}

\author{
Samilly Silva Miranda* \\ Kamilla Silva Miranda** \\ Arthur Nunes Rios Vicente ${ }^{* * *}$ \\ Gabriela Sampaio Campos** \\ Juliana Amaral Bulcão** \\ Lílian de Jesus Neves ${ }^{* * *}$
}

\section{Resumo}

Objetivo: o presente artigo objetiva explorar a Legislação Trabalhista nas possíveis relações de trabalho do cirurgião-dentista, apontando as nuances da temática e demonstrando a relevância do cumprimento dos diplomas normativos aplicáveis à classe odontológica na esfera pública e privada. Revisão da literatura: a relação de emprego tem como principal característica a presença do empregado associada à existência de requisitos essenciais para configurar vínculo empregatício. Por meio da Consolidação das Leis do Trabalho (CLT) a classe terá direitos e deveres assegurados, podendo exercer atividades que não configuram vínculo empregatício, como trabalhador autônomo ou cooperado. Considerações finais: observa-se que cabe ao profissional reconhecer a relevância social da sua profissão, de maneira a direcionar o mercado no sentido de exigir que Ihe seja assegurado todos os direitos a que faz jus e que, em resposta, apresentará atividades de qualidade, alcançando o seu fim maior de promover saúde àqueles que lhe confiam esse papel.

Palavras-chave: Legislação trabalhista. Emprego. Odontologia legal.

\section{Introdução}

$\mathrm{Na}$ atualidade, revela-se imensamente importante o conhecimento do Direito do Trabalho. Diante das constantes mudanças nas relações entre capital e trabalho, apenas se consegue programar estratégias de crescimento profissional quando se está adequado aos padrões exigidos pela legislação.

Essas mudanças defluem de fenômenos como a globalização dos mercados, o aumento da competitividade entre países ou empresas, a reestruturação produtiva, as inovações tecnológicas e/ou socio-organizacionais, a flexibilização das relações de trabalho, dentre outras ${ }^{1}$.

Destarte, com o escopo de acompanhar as mudanças do mercado, é oportuna a observância às normas que enfatizam os princípios e as condutas sociais associadas às obrigações e aos direitos do trabalhador. Tais normas funcionam como padrões sociais que balizam as avaliações individuais acerca das recompensas obtidas pelo trabalho e consistem numa expressão geral do que seriam trocas equitativas entre o que 0 indivíduo recebe da situação de trabalho e as contribuições que ele traz para o processo de trabalho.

Mestranda em Saúde Coletiva pela Universidade Estadual de Feira de Santana (UEFS). Graduada em Odontologia, Universidade Estadual de Feira de Santana, Bahia, Brasil.

Pós-graduada em Direito Público, pelo Instituto de Educação Superior Unyahna. Bacharel em Direito pela União Metropolitana de Educação e Cultura (Unime), Bahia, Brasil.

*** Graduados em Odontologia pela Universidade Estadual de Feira de Santana, Bahia, Brasil. 
Esse cenário também se manifesta no âmbito da odontologia, no qual a relação empregado/empregador faz-se necessária para regular a execução das atividades odontológicas, razão pela qual, com o fito de manter um relacionamento profissional entre os envolvidos naquelas atividades, resta imperioso a observância das legislações trabalhistas e correlatas, consoante expressamente estabelece o art. 13, inciso VII, do Código de Ética Odontológico.

Nesse ínterim, objetiva-se, por meio de uma revisão bibliográfica, explorar a Legislação Trabalhista nas possíveis relações de trabalho do Cirurgião Dentista, apontando as nuances da temática e demonstrando a relevância do cumprimento dos diplomas normativos aplicáveis à classe odontológica nas esferas pública e privada.

\section{Revisão de Literatura}

O Direito do Trabalho é o ramo da ciência do Direito que tem por objetivo as normas, as instituições jurídicas e os princípios que disciplinam as relações de trabalho, determinam os seus sujeitos e as organizações destinadas à proteção desse trabalho em sua estrutura e atividade.

Impõe esclarecer que a expressão relação de trabalho na seara do Direito Trabalhista contempla todas as relações jurídicas que consubstanciam uma obrigação proveniente do trabalho humano, englobando a relação de emprego, a relação de trabalho autônomo, a relação de trabalho eventual e a de trabalho avulso, apresentando-se, pois, como uma expressão genérica.

O presente artigo limitar-se-á a demonstrar quais os sujeitos e os requisitos para se configurar a relação de emprego, para posterior discussão acerca das particularidades do Cirurgião Dentista na condição de empregado, autônomo e cooperativado, exercendo, pois, em todas elas, relação de trabalho.

\section{Sujeitos da relação de emprego}

A relação de emprego tem como principal característica a presença do empregado, figura esta protegida pelo Direito do Trabalho. Trata-se a relação individual de emprego de um negócio jurídico estabelecido, voluntariamente, entre empregados e empregadores, firmando direitos e obrigações para ambos os sujeitos, observados os patamares mínimos previstos em lei ${ }^{2}$.

Para compreender a relação entre estes sujeitos, é preciso conhecer os conceitos legais de empregador e empregado delimitados nos arts. $2^{\circ}$ e $3^{\circ}$ da Consolidação das Leis do Trabalho (CLT).

De acordo com o conceito legal "considera-se empregador a empresa, individual ou coletiva, que, assumindo os riscos da atividade econômica, admite, assalaria e dirige a prestação pessoal de serviços" (art. $2^{\circ}, \mathrm{CLT}$ ). O empregador é, portanto, a pessoa física ou jurídica que assume a responsabilidade legal e coordena todo o processo de contratação.

Quanto ao empregado, o art. $3^{\circ}$ da CLT considera-o "toda pessoa física que prestar serviços de natureza não eventual a empregador, sob a dependência dele e mediante salários", isto é, aquele que tem deveres e obrigações a serem cumpridas e direitos a serem protegidos.

\section{Requisitos da relação empregatícia}

À luz da Consolidação das Leis do Trabalho, especialmente do teor dos dispositivos transcritos acima, é possível extrair cinco requisitos essenciais à configuração do vínculo empregatício, a saber ${ }^{3}$ :

- pessoa física: o empregado é pessoa física ou natural, visto que a lei trabalhista foi criada para proteger o ser humano, excluído, portanto a figura de pessoa jurídica;

- não eventualidade: é necessário que o trabalho realizado não seja eventual, pois o contrato de trabalho exige continuidade de tempo;

- onerosidade: a prestação de serviços é onerosa, haja vista que de um lado o empregado assume a obrigação de prestar serviços, de outro, o empregador tem a obrigação de pagar salário;

- subordinação: o empregado deve trabalhar sob a dependência do empregador, já que esse assume todos os riscos do empreendimento, adquirindo dessa forma, o poder de organizar e dirigir a prestação de serviços;

- pessoalidade: as obrigações do empregado apenas poderão ser por eles desenvolvidas, considerada incabível a delegação a terceiros promovida pelo próprio empregado.

- requisitos não essenciais à configuração da relação de emprego;

- exclusividade: não há, na CLT, a exigência de que o empregado preste serviços com exclusividade, podendo este ter carteira assinada por vários empregadores ${ }^{3}$;

- local da prestação de serviços: fato presente no art. $6^{\circ}$ da CLT, quando aponta que "não se distingue entre o trabalho realizado no estabelecimento do empregador e o executado no domicílio do empregado, desde que esteja caracterizada a relação de emprego"’.

\section{Discussão}

Ao compreender que relação de emprego é aquela que se configura entre um empregado e um empregador, regendo-se pelos artigos $2^{\circ}$ e $3^{\circ}$ da CLT, sendo na prática identificada por meio do contrato de emprego, que nada mais é do que o ajuste verbal ou escrito, tácito ou expresso, firmado entre o empregado, que assume a obrigação de, pessoalmente, prestar serviços não eventuais e subordinados, e o empregador, que assume a obrigação de pagar salário. 
Adequando-se ao cenário da legislação trabalhista, no âmbito da relação de emprego com cirurgiões-dentistas, os contratos podem ser firmados por prazo determinado ou indeterminado. O primeiro pode ser preferível pelo empregador por trazer vantagens quanto à impossibilidade de o empregado adquirir estabilidade, da não necessidade de conceder aviso prévio, além de não ser necessário o pagamento da indenização de $40 \%$ sobre os depósitos do Fgts. Ademais, o contrato individual de trabalho poderá ser acordado tácita ou expressamente, verbalmente ou por escrito.

Quanto ao término desse tipo de contrato, poderá ocorrer de duas maneiras: pela extinção normal, na qual o empregador deverá pagar as verbas rescisórias referentes ao período de trabalho (saldo de salário dos dias trabalhados, $13^{\circ}$ salário proporcional ao tempo trabalhado e férias mais $1 / 3$ proporcional ao tempo trabalhado) e de maneira antecipada, ou seja, antes do prazo fixado pelas partes, fixado previamente ou não, devendo haver pagamento de indenização, que será de acordo com quem deu causa ao desligamento, seguindo os parâmetros existentes na CLT ${ }^{4}$.

Nos contratos firmados por tempo indeterminado, por seu turno, a tendência é que se prolongue no tempo, haja vista a inexistência do prazo para o seu término. Nada obstante, fatores internos e externos podem ser determinantes quanto à manutenção da relação contratual, que poderá ser extinta por mera liberalidade do empregado, pela vontade do empregador (extinção do contrato sem justa causa) e em virtude de algum comportamento desmedido do empregado (extinção do contrato com justa causa). Assinala-se que essas três modalidades de rescisão do contrato ensejam direitos e obrigações variáveis quanto ao FGTS, ao aviso prévio, a férias e ao $13^{\circ}$ salário proporcionais.

Cabe destacar que a continuidade das atividades profissionais decorrentes de um contrato de trabalho de prazo determinado quando já esgotada a sua vigência, transmuda-o em contrato por prazo indeterminado.

Lenzi et al. $^{5}$ (2010), ao analisar o perfil dos cirurgiões-dentistas integrantes do Programa de Saúde da Família de um município no Sul do Brasil, observaram que $100 \%$ da amostra ingressaram no Programa de Saúde da Família (PSF) por meio de contrato temporário, o, que por sua vez, coloca a perspectiva do futuro profissional no PSF atrelada às mudanças políticas.

Ademais, o cirurgião-dentista ainda pode desenvolver trabalho autônomo, isso é, aquele sem subordinação jurídica inerente a um contrato de trabalho. O indivíduo pode negociar mais livremente as relações profissionais, regulando sua carga de trabalho, seus horários e o valor de seus serviços ${ }^{6}$.

O art. $4^{\circ}$, alínea c, da Lei $\mathrm{n}^{\circ} 3.807 / 1960$, com redação dada pela Lei $\mathrm{n}^{\mathrm{o}} 5.890 / 1973^{7}$, considera o trabalhador autônomo como:
[...] o que exerce habitualmente, e por conta própria, atividade profissional remunerada; o que presta serviços a diversas empresas, agrupado ou não em sindicato, inclusive os estivadores, conferentes e assemelhados; o que presta, sem relação de emprego, serviço de caráter eventual a uma ou mais empresas; o que presta serviço remunerado mediante recibo, em caráter eventual, seja qual for a duração da tarefa.

Tendo em vista que o trabalhador autônomo desenvolve suas atividades sem subordinação à figura do empregador, ele próprio ajusta os serviços e o preço, podendo atuar ou não com a ajuda de terceiros. O autônomo não é empregado, não se submetendo, pois, às preceituações da CLT ${ }^{8}$. É nesse cenário de atuação por conta própria, como o profissional liberal, que se enquadram a maioria dos cirurgiões-dentistas, optando pela montagem do seu consultório particular, comercializando conhecimento e técnica.

Bastos et al. ${ }^{9}$ (2003) realizaram estudo no qual procuraram delinear o perfil profissional de cirurgiões-dentistas graduados pela Faculdade de Odontologia de Bauru - USP, entre 1996 e 2000, encontrando como resultado predominância de cirurgiões-dentistas atuando em consultórios particulares.

Outro estudo mais recente, realizado em Santa Catarina, também alcançou resultados semelhantes, com o grupo de cirurgiões-dentistas pesquisados caracterizando-se expressivamente por especialistas em área clínico-curativa, agindo prioritariamente como profissional autônomo ${ }^{10}$.

Araújo e Mello ${ }^{11}$ (2010), em publicação intitulada $O$ cirurgião-dentista: estudo exploratório sobre Perfil, Formação e Exercício Profissional no Estado da Bahia, de 2007, encontraram numa amostra de 300 indivíduos, 80,3\% com atuação predominante em consultórios particulares, num período de dois a dez anos.

É preciso também atentar para o fato de que muitos profissionais que exercem a prática privada e se autodeclaram profissionais liberais autônomos também se reconhecem dependentes dos convênios /credenciamentos, que poderiam ser percebidos como uma forma de "assalariamento indireto"12.

Apesar de se caracterizar por uma relação sem interferências entre paciente e profissional, independência no exercício da atividade e livre ajustamento dos rendimentos entre as partes interessadas, no trabalho autônomo, o profissional necessita ter atributos, como iniciativa, auto-organização e discricionariedade.

Finalmente, os profissionais da área da odontologia podem ainda fazer parte de cooperativas, que correspondem às sociedades de pessoas, não sujeitas à falência, que contribuem com bens e serviços para o exercício de uma atividade econômica sem objetivo de lucro ${ }^{13}$. Os interesses individuais em produzir, comercializar ou prestar serviço não devem conflitar com os objetivos gerais da cooperativa ${ }^{14}$.

Nesse tipo de sociedade não há subordinação entre os membros, e sim, regime de contribuição ${ }^{15}$. As cooperativas proporcionam mais vantagens econômicas aos associados, com recolhimento somente 
das taxas de administração, de INSS e ISS; de caráter civil, o que desobriga também o trabalhador de qualquer contribuição sindical ${ }^{14}$.

Segundo art. 90 da Lei $n^{\circ} 5.764 / 1971$, qualquer que seja o tipo de cooperativa, não existe vínculo empregatício entre ela e seus associados, igualando-se as cooperativas às demais empresas em relação aos seus empregados para os fins da legislação trabalhista e previdenciária (art. 91) ${ }^{13}$.

As cooperativas odontológicas operam exclusivamente planos odontológicos, e surgiram como respostas aos problemas de irregularidades cometidas por determinados convênios odontológicos, principalmente no que se refere à relação entre as operadoras e os profissionais credenciados ${ }^{15}$.

A Uniodonto, fundada em 1972, é um exemplo, e atualmente reúne mais de 20.000 cirurgiões dentistas cooperados. Travaglini (2003) apud Schiavolin Neto $^{15}$ (2005) descreve que as cooperativas odontológicas se diferenciam em diversos aspectos dos convênios, principalmente, no que se refere a uma atuação mais participativa e menos submissa, o cooperado é também sócio e pode tomar decisões em assembleias, além disso, como as cooperativas não visam lucro, elas repassam um valor maior aos dentistas pelos serviços prestados, se comparadas aos convênios.

\section{Considerações finais}

À luz dos ensinamentos ora expostos é perceptível que ao cirurgião-dentista são assegurados direitos decorrentes das relações de trabalho por ele desenvolvidas. Desse modo, observa-se que cabe ao próprio cirurgião-dentista, reconhecendo a relevância social da sua profissão, direcionar o mercado no sentido de exigir que lhe sejam assegurados todos os direitos a que lhe fazem jus e que, em resposta, apresentará atividades de qualidade, alcançando o seu fim maior de promover saúde.

\section{Agradecimento}

Os autores agradecem à Jenny Smolen por contribuir na construção do abstract.

\section{Abstract}

Objective: This article aims to explore the Labor Legislation regarding the possible work relationships of Dental Surgeons, pointing out the nuances of the subject and demonstrating the relevance of compliance with regulatory instruments applicable to the dental profession in public and private spheres. Literature review: The main characteristic of work relationships is the presence of an employee, associated with the existence of essential requirements to establish an employment bond. Through the Consolidation of Labor Laws (CLT) workers will have secured rights and duties. Moreover, they will be able to work in activities that do not determine employment bonds, such autonomous or cooperative activities. Final considerations: It is observed that is up to professionals to recognize the social relevance of their profession, in order to direct the market towards demanding that all their rights are secured and, in response, they will perform quality work, achieving the larger goal of promoting the health of those who entrusted him with this role.

Keywords: Labor legislation. Employment. Forensic dentistry.

\section{Referências}

1. Tolfo SR, Piccinini V. Sentidos e significados do trabalho: explorando conceitos, variáveis e estudos empíricos brasileiros. Psicologia \& Sociedade 2007;19, Edição Especial, 1:38-46.

2. Moura M. Consolidação das Leis do Trabalho. 2. ed. Salvador: JusPodivm; 2012.

3. Correia H. Direito do Trabalho: para os concursos de analista do TRT e do MPU. 2. ed. Salvador: JusPodivm; 2011.

4. Brasil. Decreto-lei $\mathrm{n}^{\circ} 5.452$, de 01 de Maio de 1943 [acesso em 20 out. 2014]. Disponível em URL: http://www.planalto.gov. br/ccivil_03/decreto-lei/del5452.htm.

5. Lenzi TL, Rocha RO, Dotto PP, Raggio DP. Perfil dos cirurgiões-dentistas integrantes do Programa Saúde da Família em um município do Sul do Brasil. J Health Sci Inst 201028(2):121-4

6. Villela FG. Manual de Direito do Trabalho. Rio de Janeiro/ Campus: Elsevier; 2012.

7. Brasil. Lei no 5.890 de 8 de Junho de 1973 [acesso em 14 nov. 2014]. Disponível em URL: http://www3.dataprev.gov.br/ SISLEX/paginas/42/1997/..\%5C1973\%5C5890.htm.

8. Pretti G. Direito do Trabalho para Concursos. Curitiba-PR: IEDE; 2011.

9. Bastos JRM, Aquilante AG, Almeida BS, Lauris JRP, Bijella VT. Análise do perfil profissional de cirurgiões-dentistas graduados na Faculdade de Odontologia de Bauru - USP entre os anos de 1996 e 2000. J Appl Oral Sci 2003;11(4):283-9.

10. Neto UM, Oliveira LK, Tames SFA, Bottan ER, Silveira EG, Bueno RN. Perfil profissional de um grupo de cirurgiões-dentistas em atuação no estado de Santa Catarina - Brasil. Rev Ciências da Saúde 2012;31(1):7-17

11. Araújo RPC, Mello SMF. O cirurgião-dentista: estudo exploratório sobre perfil, formação e exercício profissional no Estado da Bahia. Salvador: EDUFBA; 2010. 252 p.

12. Moysés SJ. Políticas de saúde e formação de recursos humanos em Odontologia. Rev ABENO 2004;4(1):30-7.

13. Brasil. Lei n. 5.764/71. Define a Política Nacional de Cooperativismo, institui o regime jurídico das sociedades cooperativas, e dá outras providências, de 16 de dezembro de 1971.

14. Crúzio HO. Como organizar e administrar uma cooperativa. Rio de Janeiro: FGV; 2000.

15. Schiavolin Neto L. Convênio e cooperativas odontológicas na região metropolitana de São Paulo: uma análise operacional. [Dissertação de Mestrado]. São Paulo: Universidade Estadual de Campinas, Faculdade de Piracicaba; 2005.

\section{Endereco para correspondência:}

Carlos Eduardo Zanella Pasquali

Tomaz Flores, no 82/905-Bairro Independência 90035-200 Porto Alegre-RS

Telefone: (51) 9375-5552

E-mail: pasquali.carlos@hotmail.com

Recebido: 27/02/2015. Aceito: 23/03/2015. 